“ (C) 2016 IEEE. Personal use of this material is permitted. Permission from IEEE must be obtained for all other uses, in any current or future media, including

reprinting/republishing this material for advertising or promotional purposes, creating new collective works, for resale or redistribution to servers or lists, or reuse of any copyrighted component of this work in other works." 


\title{
Investigation of Microwave Active Elements Embedded in Composite Structures
}

\author{
Thomas C. Baum", Kamran Ghorbani, Richard W. Ziolkowski ${ }^{+}$and Kelvin J. Nicholson* \\ \#School of Engineering, RMIT University, Melbourne, VIC, Australia \\ ${ }^{+}$Department of Electrical and Computer Engineering, University of Arizona, Tucson, AZ 85721 \\ *DST Group, Fishermans Bend, Melbourne, VIC, Australia
}

\begin{abstract}
Multifunctional structures have become popular within the past decade as they allow for more efficient utilization of limited real-estate available on many civilian and military platforms. Taking structures and electromagnetics, one can marry these two fields to produce a weight optimized loadbearing microwave structure which may ideally be suited for unmanned aerial systems. This paper investigates the use of textile processes to develop loadbearing smart skins built into a class of structural conformal composite materials called prepregs (resin pre-impregnated fabrics). An example of an active UWB mini-circuits ERA-4SM+ (0-4 GHz) amplifier has been investigated within a $48 \mathrm{~g} . \mathrm{m}^{-2}$ pre-preg structural glass material (HexPly914E). This amplifier has been embroidered and cured at $170^{\circ} \mathrm{C}$ in an autoclave at $700 \mathrm{kPa}$ pressure. Its performance before and after curing has been examined.
\end{abstract}

Index Terms - Composites, multifunctional structures, pregtronics, UWB amplifiers.

\section{INTRODUCTION}

Embroidery of conductive threads into textile materials has been used to create conformal and wearable circuits [1]-[7]. These have been used in a variety of fields including health monitoring for the age care sector, sport/athlete performance monitoring, military applications and even space EVA suites [1]-[7].

The primary issues involved with wearable systems are the poor effective conductivity of commercially available threads or fabrics. This leads to significant loss and so limits high frequency RF applications such as antennas [8]-[10]. Although these challenges are slowly being overcome for textile devices, very little work has been carried out on another class of textiles commonly used within the aerospace industry. These textile materials are commonly made from glass fiber reinforced polymers (GFRP), carbon fiber reinforced polymers (CFRP) or Kevlar composites.

Unlike textiles, aerospace composites fall under a class of systems referred to as multifunctional structures. It was demonstrated in [11] that antenna structures can be integrated efficiently into aero-structures to create a multifunctional loadbearing conformal slotted waveguide array (SWASS program). Recent developments have illustrated the use of light weight honey comb panels with integrated patch arrays [12].

The notion of smart skins generalized the ability to integrate more complex systems into composite skin panels [13]. The primary purpose behind this high integration is to better utilize the limited real-estate on many platforms (i.e. aircraft, spacecraft, land vehicles or sea vessels) and to optimize the weight of these structures. For aerospace platforms this also includes other critical flight parameters (such as drag reduction) which all accumulate to save operational costs through fuel burn reduction.

Recently the authors have investigated the conductivity of the threads, which are sewn into pre-preg composite materials. Different sewing and stitches techniques, and tread types were considered [14]. This paper investigates the design and integration of an embroidered UWB mini-circuits ERA-4SM+ (0-4 GHz) amplifier into an epoxy pre-impregnated (pre-preg) structural glass (S-Glass) material call HexPly 914E. Prepregs are unique and well established materials in the aerospace industry since they allow for optimal fiber-volume fraction to be reached within the composite structure.

The HexPly 914E is flexible and conformal at room temperature until it is cured at $170{ }^{\circ} \mathrm{C}$ and at $700 \mathrm{kPa}$ of pressure. Any embroidered conductive threads and / or other devices / lumped elements must survive this harsh curing cycle. One advantage of this process however is the extremely good consolidation achieved during the curing process. Unlike traditional textile devices, the conductive threads are squeezed together during the cure cycle. This significantly improves there effective conductivity.

\section{Conductive Thread Performance}

The conductive thread used to develop the UWB amplifier was purchased from Shieldex (100/34 dtex 2ply HC). The performance of the fiber within the HexPly 914E pre-preg using three different stitching techniques were evaluated. The insertion performance of a $100 \mathrm{~mm}$ embroidered microstrip using a duel needle/bobbin technique has been illustrated in Fig. 1. The three different stitching techniques evaluated use the conductive fiber as the needle thread (needle only), as both 
the needle and bobbin thread and as the bobbin thread. Two non-conductive fibers were evaluated for the needle stitching and the bobbin stitching techniques. These were polyester and Kevlar fiber. No measurement variation was seen between these two fibers. The needle only case is the most conventional way of embroidering threads into textiles. The needle/bobbin illustrated in Fig. 1 consist of the average of 9 microstrip lines stitched with a running pitch of $2 \mathrm{~mm}$ and a line density of $4 \mathrm{l} / \mathrm{mm}$.

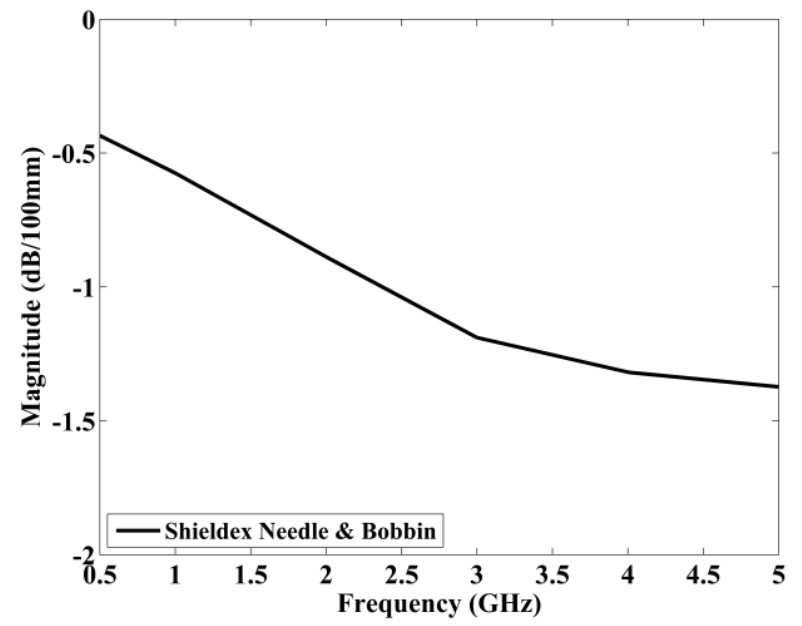

Fig. 1. Average RF performance of embroidered Shieldex fibers (normalized to a copper microstrip line) into the HexPly 914E SGlass. Evaluations of three different stitching techniques have been illustrated.

The best performance is attributed to the low friction wearing of the conductive fiber within the bobbin. The bobbin thread only passes through a single tensioner unlike the needle thread which passes through several tensioners. This constant wearing breaks down the conductive layer reducing its overall conductivity. The needle and bobbin stich is between the two extremities as it contains half of the degraded needle thread and half of the well preserved bobbin thread. One disadvantage of the bobbin stitch techniques is that the structure must be sewn upside down. When embroidering complex structures this adds complexity to the manufacturing process. For this reason a needle and bobbin stitch has been chosen for evaluation of the manufacture of the UWB amplifier. Also, it must also be noted that the successful measurement of the microstrip lines demonstrates that the Shieldex fiber will survives the extreme autoclave curing process.

\section{MANUFACTURE OF A UWB AMPLIFIER}

Using the measured properties of the microstrip in Section II above, a CST microwave studio (MWS) 2015 hybrid simulations was carried out to evaluate the performance of an ideal UWB amplifier. A commercial of the shelf mini-circuits ERA-4SM+ (0-4 GHz) was chosen as it has wideband performance, internally matched to $50 \Omega$ and is extremely cheap. S-parameters supplied by the amplifier manufacturer were co-simulated with a DC blocking cap (as recommended by the mini-circuits ERA-4SM+ evaluation board datasheet) and a simple microstrip line. The final two steps of the manufacturing process are illustrated in Fig. 2. Fig. 2a illustrates the pre-preg post embroidery. Prepared are the ERA-4SM+ components and a ceramic DC blocking cap on small copper tabs. Note the loops present on the ERA-4SM+.

a)

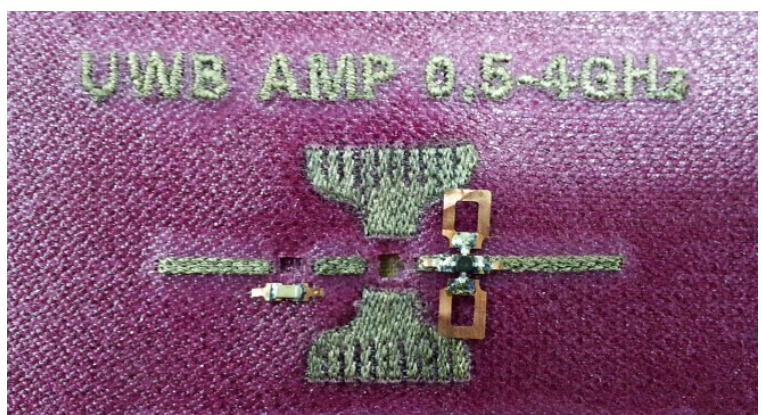

b)

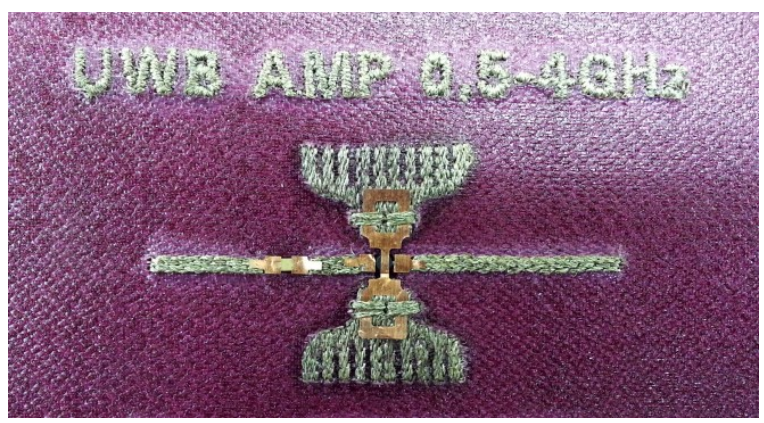

Fig. 2. a) initial manufacture of the HexPly 914E pre-preg panel sewn with the Shieldex fiber pattern and b) the completed manufactured amplifier showing embroidered strapping to hold the ERA-4SM+ into place.

These loops are used to strap and hold the ERA-4SM+ into the composite panel. Fig. $2 \mathrm{~b}$ show this strapping process. Also, it must be noted that the ERA-4SM+ and DC blocking cap have been flipped so that it will be embedded into the composite structure. This has been done so that both components are less susceptible to environmental ingress. Also, for aerospace applications, a smooth conformal skin is desired. Perturbing components will add to skin roughness and thus will increase skin drag.

To complete the manufacturing, copper tabs were added on top of the embroidered microstrip lines and two plies of extremely fine $72 \mathrm{~g} / \mathrm{m}^{2}$ copper mesh were added to create a ground plane. The entire composite panel was then consolidated using a process called de-bulking before it was placed into the autoclave for final curing. The curing process for the HexPly 914E was supplied by HexCell Cooperation.

\section{TESTING OF A UWB AMPLIFIER}

The cured panel was cut to size and SMA connectors soldered into place. This was made easy by the inclusion of 
the small copper tabs during the manufacturing process. The adhesion of the epoxy resin and the consolidation pressure are more than sufficient to create electrical contact with the embroidered fibers. This is not possible with wearable textiles. An external HP bias-tee is used to supply the biasing voltage to the ERA-4SM+.

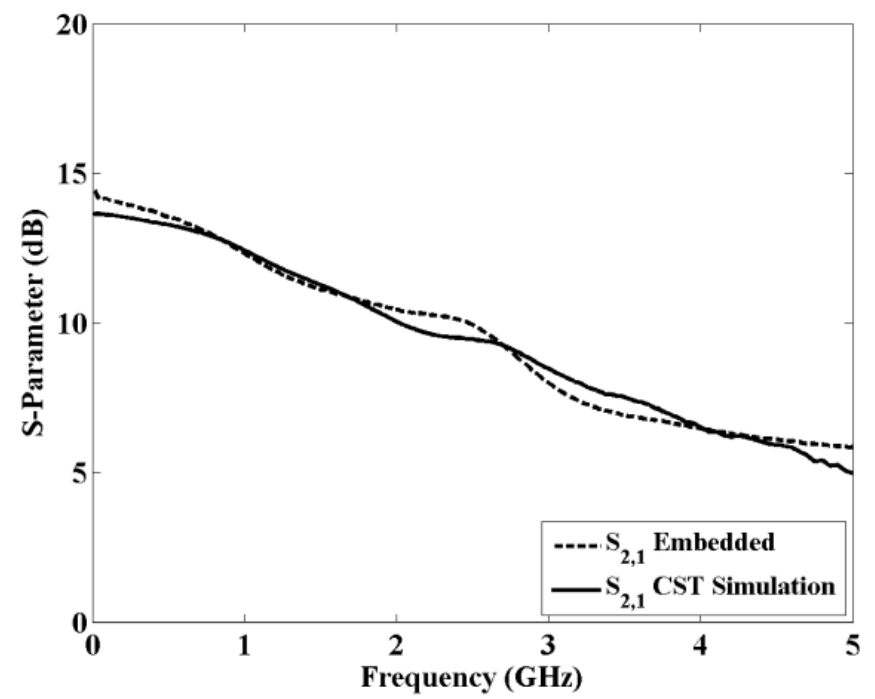

Fig. 3. Acomparison between simulated and measured results obtained for the ERA-4SM+ amplifier.

The measured results of the consolidated amplifiers and the co-simulation carried out in CST MWS are illustrated in Fig. $3 \mathrm{~b}$. The results show excellent agreement. Furthermore, the amplifier has survived the autoclave process with little (if any) performance reduction. Also, the flipping and embedding of the ERA-4SM+ has not shown to cause any degradation in RF performance. This result clearly demonstrates the integration of active and lumped elements into structural materials. However, the structural implications of this integration must also be evaluated.

\section{CONCLUSION}

It has been demonstrated that active RF Components can be integrated into common aerospace composite materials. Using textile based embroidery, it was shown that the bobbin stitching resulted in the highest conductivity. However, this was shown to not always be optimal given the limitations of the fabrication process. A gain of $+10 \mathrm{~dB}$ was recorded at 2 $\mathrm{GHz}$ for the UWB amplifier. Both simulation and measurement were in very good agreement. The successful testing of the embedded amplifier clearly demonstrated its durability in spite of the autoclave process. Hence, this work has demonstrated the feasibility of multifunctional conformal structures and smart skins. This new storable, loadbearing, conformable, multifunctional smart structure concept has been dubbed 'pregtronics' in reference to the preg-preg materials and integrated electronic components.

\section{ACKNOWLEDGEMENT}

This work was supported by the Australian Department of Defense, Defense Science and Technology Group (DSTG) SRI-SME. The initial contributions by RWZ to this work occurred as the 2014-2015 Australian DSTO Fulbright Distinguished Chair in Advanced Science and Technology. He especially would like to thank the Australian-American Fulbright Commission and the Defense Sciences and Technology Group (formally DSTO) for their support.

\section{REFERENCES}

[1] L. Ma, R. M. Edwards, S. Bashir and M. I. Khattak, "A wearable flexible multi-band antenna based on a square slotted printed monopole," in Proc. Loughborough Antennas Propag. Conf., LAPC 2008, Loughborough, UK, Nov. 2008, pp. 345-348.

[2] L. Ma, R. M. Edwards and W. G. Whittow, "A notched hand wearable ultra wideband w printed monopole antenna for sporting activities," in Proc. Loughborough Antennas Propag. Conf., LAPC 2008, Loughborough, UK, Nov. 2008, pp. 397-400.

[3] N. H. M. Rais, P. J. Soh, F. Malek. S. Ahmad, N. Hashim and P. Hall, "A review of wearable antenna," in Proc. 2009 Loughborough Antennas Propag. Conf., LAPC 2009, Loughborough, UK, Nov. 2009, pp. 225228.

[4] P. Hall, Y. Hao and S. Cotton, "Advances in antennas and propagation for body centric wireless communications," in Proc. Fourth European Conf. Antennas Propag., EuCAP2010, Barcelona, Spain, Apr. 2010, pp.1-7.

[5] L. Zhang, Z. Wang and J. L. Volakis, "Textile antennas and sensors for body-worn applications," IEEE Antennas Wirel. Propag. Lett., vol. 11, pp. 1690-1693, 2012.

[6] T. Kaufmann and C. Fumeaux, "Wearable textile half-mode substrateintegrated cavity antenna using embroided vias," IEEE Antennas Wirel. Propag. Lett., vol. 12, pp. 805-808, 2013.

[7] T. Haagenson, S. Noghanian, P. de Leon, and C. Yi-hsiang, "Textile Antennas for Spacesuit Applications: Design, simulation, manufacturing, and testing of textile patch antennas for spacesuit applications," IEEE Ant. Propag. Mag.e, vol. 57, pp. 64-73, 2015.

[8] I. Locher, M. Klemm, T. Kirstein, and G. Troster, "Design and Characterization of Purely Textile Patch Antennas," IEEE Trans. Adv. Packag., vol. 29, pp. 777-788, 2006.

[9] W. Zheyu, Z. Lanlin, Y. Bayram, and J. L. Volakis, "Embroidered Conductive Fibers on Polymer Composite for Conformal Antennas," , IEEE Trans. Ant. Propag., vol. 60, pp. 4141-4147, 2012.

[10] A. Chauraya, S. Zhang, W. Whittow, T. Acti, R. Seager, T. Dias, et al., "Addressing the challenges of fabricating microwave antennas using conductive threads," 2012 6th European Conference on Antennas and Propagation (EUCAP), pp.1365-1367, 26-30 Mar, 2012.

[11] P. J. Callus, "Novel concepts for conformal load-bearing antenna structure," Defence Science and Technology Organisation (DSTO)2008.

[12] Z. Jinzhu, H. Jin, S. Liwei, Z. Dan, and M. Yunchao, "Electromechanical co-design and experiment of structurally integrated antenna," Smart Materials and Structures, vol. 24, p. 037004, 2015.

[13] M. A. Hopkins,. J. M. Tuss, A. J. Lockyer, K. Alt, R.t Kinslow, and J. N. Kudva. "Smart skin conformal load-bearing antenna and other smart structures developments." In Proceedings of the 38th AIAA/ASME/ASCE/AHS/ASC, structures, structural dynamics and materials conference, pp. 521-530. 1997.

T. C. Baum, R. W. Ziolkowski, K. Ghorbani and K. J. Nicholson, " Embroidered Active Microwave Aerospace Composite Pre-Pregs Electronics - Pregtronics," to be published. 